\title{
The impact of the nurses', doctors' and clinical officer strikes on mortality in four health facilities in Kenya
}

\author{
Grace Kiringa Kaguthi ${ }^{{ }^{*}} \mathbb{D}$, Videlis Nduba ${ }^{1}$ and Mary Beth Adam $^{2}$
}

\begin{abstract}
Background: Health worker strikes are a significant threat to universal access to care globally and especially in sub Saharan Africa. Kenya's health sector has seen an increase in such industrial action. Globally there is limited data that has examined mortality related to such strikes in countries where emergency services were preserved. We sought to assess the mortality impact of an 100 day physician strike which was followed by 151 day nurses' strike and 20 day clinical officer strike in Kenya.

Methods: Monthly mortality data was abstracted from four public hospitals, Kenyatta National Referral Hospital, AIC Kijabe Hospital, Mbagathi Hospital and Siaya Hospital between December 2016 and March 2018. Differences in mortality were assessed using t-tests and multiple linear regression adjusting for facility, numbers of patients utilizing the hospital and department.

Results: There was a significant decline in the numbers of patients seen, comparing the non-strike and strike periods; beta (B) coefficient - $649(95 \% \mathrm{Cl}-950,-347) p<0.0001$. The physicians' strike saw a significant decline in mortality (B) coefficient $-19.0(95 \% \mathrm{Cl}-29.2,-8.87) p<0.0001$. Nurses and Clinical Officer strikes' did not significantly impact mortality. There was no mortality increase in the post-strike period beta (B) coefficient $7.42(95 \% \mathrm{Cl}-16.7$, 1.85) $p=0.12$.

Conclusion: Declines in facility-based mortality during strike months was noted when compared to a non-striking facility, where mortality increased. The decline is possibly associated with the reduced patient volumes, and a possible change in quality of care. Public health facilities are congested and over-utilized by the local population majority of whom cannot afford even low cost private care. Health worker strikes in Kenya where the public health system is the only financially accessible option for $80 \%$ of the population pose a significant threat to universal access to care. Judicious investment in the health infrastructure and staffing may decrease congestion and improve quality of care with attendant mortality decline.
\end{abstract}

Keywords: Strikes, Mortality, Doctors, Nurses, Clinical officers, Universal health care, Kenya

\footnotetext{
*Correspondence: skiringa@gmail.com

${ }^{1}$ Centre for Respiratory Diseases Research-Kenya Medical Research Institute (KEMRI-CRDR), P.O. Box 62269-00200, Nairobi, Kenya

Full list of author information is available at the end of the article
}

(C) The Author(s). 2020 Open Access This article is licensed under a Creative Commons Attribution 4.0 International License, which permits use, sharing, adaptation, distribution and reproduction in any medium or format, as long as you give appropriate credit to the original author(s) and the source, provide a link to the Creative Commons licence, and indicate if changes were made. The images or other third party material in this article are included in the article's Creative Commons licence, unless indicated otherwise in a credit line to the material. If material is not included in the article's Creative Commons licence and your intended use is not permitted by statutory regulation or exceeds the permitted use, you will need to obtain permission directly from the copyright holder. To view a copy of this licence, visit http://creativecommons.org/licenses/by/4.0/ The Creative Commons Public Domain Dedication waiver (http://creativecommons.org/publicdomain/zero/1.0/) applies to the data made available in this article, unless otherwise stated in a credit line to the data. 


\section{Background}

The formal assessment of the impact of health workers' strikes on mortality has demonstrated counterintuitive outcomes [1] contrary to mass media reports and reported health worker concerns [2, 3]. The nurses' and doctors' strikes in Kenya generated perceptions of unmet health needs [3]. Paradoxically, studies in industrialized nations show mortality to remain the same or decline [1] under strike conditions.

Data from a different, low resourced context has been limited [4]. Poor and disadvantaged persons report higher unmet needs for health care when there are strikes [5]. Suspension of health services may have unknown effects based on the organization of the health systems in that setting, health seeking behavior, morbidity patterns and the cadre of health professionals on strike as well as level of participation.

Health systems in developing countries are subject to a myriad of challenges including drug and vaccine stockouts, understaffing and inadequate funding [6]. They're sometimes skewed to curative rather preventive services. The predominant cadre of health workers is unique in different countries. In Kenya, in almost every case, there are roughly two Clinical officers (COs) for every doctor [7]. COs are similar to physician associates or physician assistants. They are medically trained over a period of 3 years in contrast to physicians whose basic training is at least for 5 years. They're licensed to make medical decisions and are frequently the first point of contact, not the Medical Officer (MO). They retain the discretion to involve a physician in case management [8]. Contrarily, at the nation's largest teaching and referral hospital, the Kenyatta National Hospital (KNH) there are two MOs for every CO [7]. Similarly, there were 1092 General Practitioners, 3208 COs, 20,371 nurses, 419 specialist MOs. This suggests the force of the doctors' strike would be more perceptible in facilities without clinical officers.

The impacts of the strike in such a context are also influenced by health seeking behavior. Delays in seeking care have been documented for a range of illnesses not limited to tuberculosis [9, 10], malignancies [11, 12], pediatric care [13], maternal health and antenatal care [14]. Further fragility is introduced due to the difficultto-quantify effects of endemic poverty. It undermines nutritional status and affects how people prioritize health. The majority of patients (80\%) are not covered by health insurance [15]. They may not be able to afford care in private health facilities if government facilities were not fully operational. It has also been observed in developed nations, that a continuity in provision of emergency services $[1,16]$, could avert deaths and reduce the mortality impact of health worker strikes. However, the partial or complete disruption of such services in developing countries or a combination of all these factors could possibly aggravate effects of a health worker strike in developing versus developed nations [17].

\section{Kenya's health system}

To underpin this study, it's useful to examine Kenya's existing health system, infrastructure and utilization. According to the Kenya Master Health Facility List, only about $38 \%$ of Kenyan health facilities are managed by the private sector. Two of the largest public hospitals in this study are located in Nairobi where there is the largest concentration of private health facilities. That said, a considerable segment of the Kenyan population are unable to afford private sector health services and are therefore dependent on public hospitals. Reducing cost barriers to health services increased utilization of government health services demonstrated national scale changes to financing in maternity care. On June 1st 2013, government abolished user fees in all public dispensaries, health centers and all maternal health care including deliveries in all hospitals, compounding their over-utilization. Absent equivalent augmentation of facilities and personnel, this resulted in congestion, stock-outs and equipment break-down in said facilities $[18,19]$.

In addition, there were substantial data demonstrating severe staff shortages in public facilities [20]. Upon the promulgation of the new constitution in 2010, health care administration was decentralized and predominantly provided by county governments. Consequently, there was industrial action to protest this and a mass exodus of health workers, citing dilapidated health infrastructure, and underutilization of their skills.

Upstream, the strike may impact mortality and quality of care in alternative facilities. A not-for-profit hospital offering health care at a subsidized cost, recently reported increased patient volumes that exceeded the hospital's ability to respond to needs over the period of the physician strike [4].

Finally, it is emergent that not all health personnel are created equal. A twenty-year study in New York State, an industrial action hotbed, showed nurses' strikes to increase in-patient mortality and re-admission rates even after controlling for treatment intensity, disease severity and patient demographics [21]. However, there are also studies that detected no deleterious effects of nurses strikes [22, 23].

Given the variability in health systems, personnel funding, health seeking behavior, we sought to determine the impacts of the different health worker strikes in the context of a developing country, Kenya, with a view to understanding the contribution of each health worker to mortality outcomes.

The doctors' strike was occasioned by failure of government to implement an agreement signed in 2013 to 
improve remuneration, staffing and equipping of health facilities and research funding. There was a high level of participation as all doctors employed in government facilities withdrew their services. Senior doctors (consultants) and military doctors were deployed to the national referral and teaching hospital. Services were restricted to emergencies; elective procedures were deferred or asked to seek assistance in private hospitals. In peripheral government hospitals, clinical officers who often act as a filter [8], took over operations and cases that they could not manage were possibly unattended to particularly if they couldn't afford to pay for their transport to and management at private facilities. The nurses' strike agitated for better pay and implementation of their previously agreed on collective bargaining agreement. The level of curtailment of care for all the health worker strikes was nearly complete except for Kenyatta National Hospital (KNH) whose nurses did not participate with their colleagues. The $\mathrm{KNH}$ is a parastatal with different employment terms.

\section{Methods}

\section{Settings}

We selected four hospitals that represent a spectrum of health facilities available in Kenya [1]; Kenyatta National referral hospital $(\mathrm{KNH})$, which operates as a parastatal organization and whose nurses were not on strike during the 151 day nursing strike, [2] a private mission hospital, Kijabe Hospital (AICKH) whose health workers did not participate in any of the national unionized health worker industrial action, [3] a level 4 urban hospital (Mbagathi Hospital-MH) and, [4] a level 4 rural hospital (Siaya Hospital-SH).

\section{Timeline of the strikes in Kenya: duration and level of participation}

The doctors' industrial action lasted 100 days. At the inception of the doctors' strike, nurses, too were called to strike, however they returned to work after a few days after reaching an agreement with county governments. They recommenced the strike on June 5, 2017, and terminated it 5 months later in November 2017. In the midst of the nurses' strike, Clinical officers went on strike for 20 days. It has also been reported that the nurses' at AICKH went on strike for 1 week in February in the midst of the doctors' strike.

\section{Organization and selection of health facilities}

We sampled three public and one private faith led facility. All were purposively selected to include a mix of high and medium to low patient throughput and level of specialization. The latter was selected to assess for upstream effects of the strike. Geographically, two were located within Nairobi, the country's capital, one was 430 $\mathrm{km}(\mathrm{km})$ away from the capital in Western Kenya. The faith led facility was $60 \mathrm{~km}$ from Nairobi. Hospitals in the country are organized into levels one to six in ascending order based on complexity of services offered and the regional catchment it is intended to serve.

\section{Level 6 public facility (Kenyatta National Hospital-KNH)}

This is the largest national referral hospital, with a 1455 bed capacity. It serves the largest catchment area, and is a teaching hospital for the University of Nairobi, the first in the country. It's considered a tertiary facility by the ministry of health. All patients are managed by medical doctors from triage to admission and clinical officers are not involved in giving care. KNH nurses are employed by the national government under different terms and continued to work during the nurses' strike.

\section{Level 6 private facility (AIC Kijabe Hospital-AICKH)}

Located 1 hr's drive from Nairobi, it has a 363 bed capacity, employs 600 staff. It is listed as a secondary care hospital by the ministry of health. It also is a teaching facility for nurses and post-graduate doctors. Patients are triaged by clinical officers and managed by both medical and clinical officers after admission.

\section{Level 4a public facility (Mbagathi Hospital-MH)}

Considered a primary care facility, it's located within the city's capital, with a total bed capacity of 200 and staff of 328. Patients are triaged at the outpatient by medical doctors and managed thereafter by consultant physicians. Clinical officers have a nominal role.

\section{Level 4b public facility (Siaya Hospital-SH)}

This is considered a secondary care hospital, located in rural western Kenya. It was included to increase the sample diversity and generalizability of results, has a lower patient throughput and a comparably lower level of specialization of services. Patients are triaged and largely managed by clinical officers, but medical officers are available to provide care for in patients. We could not obtain accurate information on bed count and staffing.

\section{Study design}

This was an ecological survey to quantify any change in patient services and mortality during; any health worker strike period, compared to a non-strike baseline period and a 4 month post-strike period. Individual level data on diagnosis, demographics, access to care were omitted by design.

\section{Data collection}

Data on deaths and numbers of patients seen was extracted in month to month time frames, consistent with 
government reporting standards from December 2015 to March 2018. Data was obtained from the following departments: outpatient, casualty, maternity/neonatal, HIV Comprehensive Care Clinic/Anti-Retroviral Treatment Clinic (ART), surgical and medical wards. Data was aggregated as needed for specific analysis. A comparison of average monthly outpatient visits, inpatient admissions and average monthly mortality rates during the 12 prestrike months, the strike months, and post-strike months. The strike periods were as follows; (December 2016 to March 2017) for medical doctors, (June 2017 to November 2017) for nursing officers, (September 2017 to October 2017) for clinical officers. The baseline period was defined as the year preceding the strike (December 2015 to November 2016). The post-strike period was between December 2017 to March 2018, when health services were fully operational (no strikes in any cadre). These months were chosen since data are collected on a calendar-month basis. While the physician strike officially began December 5th 2016, an unofficial "go slow" mandate was in place within the public sector resulting in transfers from other facilities prior to, and in anticipation of, the formal walkout. The physician strike officially continued through March 14, 2017; however, we include the entirety of March as a strike month since all government physicians did not immediately return to work and patients remained uncertain of government service availability. The same is true of the CO strike which took place for 20 days, however the data was analysed over a 30 day month period.

Data from each department in each hospital month by month was entered on paper questionnaires and transcribed onto a Microsoft Access Database and analysed on Stata 13. (StataCorp, California US).

\section{Statistical methods}

Frequency methods were used to sum up the number of patients seen and deaths per department in each facility in the baseline period. Independent t-tests was performed to compare the mean number of patients seen per facility and mean numbers of mortalities using the private level 6 hospital as the reference, during the strike and baseline periods. AICKH was the reference facility as it was the only private facility sampled comparable to the public hospitals. Furthermore, because patient demand overwhelmed its ability during the strike period, it was evidently the next level of financially accessible health care services for thousands during the strike [4], hence a suitable benchmark for the included public facilities. Linear regression was performed to compare total deaths in the baseline, strike and post-strike periods controlling for the numbers of patients seen, facility, individual departments at the hospitals and the caliber of health worker on strike. It was also used to model the numbers of patients seen, adjusting for the period (strike vs non-strike), facility and department, to determine which factors significantly accounted for the change in volumes of patients attended to.

\section{Results}

The total numbers of patients attended to in every hospital department were aggregated year to year for the study period. During the baseline period from December 2015 to November 2016, there were no significant differences in the mean numbers of patients seen between $\mathrm{KNH}$ and AICKH and MH. However, compared to AICKH the reference facility, SH saw significantly fewer patients $(p=0.02)$. In the 4 month post-strike period, $\mathrm{KNH}$ saw more patients than the reference facility, AICKH $p=0.008$ (Table 1). Figure 1 shows the total number of patients seen versus deaths, by facility categorized by the strike or non-strike period. The non-strike period in this case aggregates the baseline pre-strike and post-strike periods.

\section{Baseline period}

At baseline (non-strike period), in-patients consistently had a significantly higher mortality in every facility. Mean outpatient deaths 14.0 (95\%CI 7.31, 20.6) vs inpatients $41.6(95 \% \mathrm{CI} 32.0,51.2) p=0.0008$. KNH had ten to twenty fold higher baseline mean mortality compared to all other facilities (Table 2).

\section{Strike period (Table 3)}

Mean baseline out-patient mortality was higher than when any cadre of staff were on strike (Table 3). This was also true for in patient mortality. However, when any cadre of staff were on strike, in-patients had higher mean mortality 32.2 (95\% CI $22.5,41.8$ ) vs outpatient $9.66(95 \%$ CI 3.76, 15.6) $p=0.007$. Nevertheless, this was still lower than the baseline period 41.6 (95\%CI 32.0, 51.2).

Adjusting for the numbers of patients seen in each facility, there were significantly fewer patients seen during the strikes compared to baseline; beta (ß) coefficient -.003 (95\% CI $-.006,-.001) p=0.003$. Compared to the baseline period, the doctors' strike saw the largest decline in mortalities, (B) coefficient - 19.0 (95\% CI -29.2, - 8.87) $p<0.0001$. The CO and nurses' strikes also saw a decline in mortality that was not statistically significant (Table 4).

Compared to the reference department (casualty/outpatient), maternity and the ART clinics had significant declines in mortality during the strike compared to the baseline period. While mortality at KNH declined in the strike period compared to baseline, the facility still had the highest mortality of all. 
Table 1 Total numbers of patients seen and respective deaths for the period under study

\begin{tabular}{|c|c|c|c|c|c|c|c|c|c|}
\hline \multirow[t]{2}{*}{ Facility } & \multicolumn{2}{|c|}{ Dec 2015-Nov2016 } & \multicolumn{2}{|c|}{ Dec 2016-Nov 2017} & \multicolumn{2}{|c|}{ Dec 2017-Mar 2018} & \multicolumn{2}{|c|}{$\begin{array}{l}\text { T-test } \boldsymbol{P} \text { value for differences } \\
\text { in patients seen } \boldsymbol{p e r} \text { year }\end{array}$} & \multirow[t]{2}{*}{$\begin{array}{l}\text { T-test } \boldsymbol{p} \text {-value fo } \\
\text { differences in } \boldsymbol{a l} \\
\text { patients seen }\end{array}$} \\
\hline & patients & deaths & patients & deaths & patients & deaths & & & \\
\hline \multicolumn{10}{|l|}{ AICKH } \\
\hline Casualty & 113,390 & 44 & 119,897 & 48 & 9114 & 4 & Dec2015-Nov2016 & (Ref) & (Ref) \\
\hline Maternity/neonatal & 1368 & 20 & 2332 & 364 & 758 & 5 & Dec2016-Nov2017 & & \\
\hline Medical/Surgical & 2614 & 212 & 2293 & 250 & 716 & 56 & Dec 2017-Mar2018 & & \\
\hline Pediatric casualty/in-patient & 2107 & 66 & 1725 & 103 & 567 & 18 & & & \\
\hline ART clinic & 5629 & 15 & 5142 & 10 & 1407 & 7 & & & \\
\hline \multicolumn{10}{|l|}{ KNH } \\
\hline Casualty & 111,243 & 1178 & 45,257 & 814 & 16,868 & 266 & Dec2015-Nov2016 & 0.07 & 0.12 \\
\hline Maternity/neonatal & 19,374 & 1822 & 15,873 & 1463 & 4551 & 400 & Dec2016-Nov2017 & 0.55 & \\
\hline Medical/Surgical & 28,264 & 4148 & 17,701 & 2973 & 7971 & 1203 & Dec2017-Mar2018 & 0.008 & \\
\hline Pediatric casualty/in-patient & 65,795 & 2911 & 42,478 & 2315 & 16,627 & 707 & & & \\
\hline ART Clinic & 31,822 & 0 & 25,824 & 0 & 9743 & 0 & & & \\
\hline \multicolumn{10}{|l|}{ MH } \\
\hline Casualty & 108,134 & 72 & 56,911 & 43 & 16,428 & 28 & Dec2015-Nov2016 & 0.88 & 0.38 \\
\hline Maternity/neonatal & 7348 & 157 & 1962 & 33 & 2591 & 39 & Dec2016-Nov2017 & 0.05 & \\
\hline Medical/Surgical & 2893 & 522 & 603 & 110 & 701 & 122 & Dec2017-Mar2018 & 0.26 & \\
\hline Pediatric casualty/in-patient & 35,814 & 142 & 16,112 & 40 & 11,134 & 37 & & & \\
\hline ART clinic & 18,435 & 16 & 15,600 & 10 & 4759 & 2 & & & \\
\hline \multicolumn{10}{|l|}{ SH } \\
\hline Casualty & 28,344 & 0 & 42,451 & 0 & 26,053 & 0 & dec2015-nov2016: & 0.03 & 0.02 \\
\hline Maternity/neonatal & 3598 & 52 & 2457 & 350 & 1308 & 27 & Dec2016-Nov2017 & 0.05 & \\
\hline Medical/Surgical & 2383 & 247 & 755 & 64 & 592 & 32 & Dec2017-Mar2018 & 0.14 & \\
\hline Pediatric casualty/in-patient & 1333 & 55 & 104 & 16 & 224 & 6 & & & \\
\hline ART clinic & 36,248 & 0 & 41,028 & & 14,282 & 0 & & & \\
\hline
\end{tabular}

There was a statistically significant decline in the numbers of patients utilizing the health facilities when doctors beta (ß) coefficient - 649 (95\% CI -951, - 347) $p<$ 0.0001 and nurses were on strike beta $(ß)$ coefficient,-353 (95\% CI -692, - 13.8) $p=0.04$, also in the post-strike period beta (ß) coefficient, $-435(95 \% \mathrm{CI}-712,-158) p=$ 0.002 , compared to baseline, but not when COs were on strike. However, the latter covered a period of 4 months only. All departments we sampled saw a decline in the numbers of patients seen, compared to casualty (Table 5).

\section{Post-strike}

There were no significant increases in mortality in the immediate period after the strike compared to baseline period beta (ß) coefficient-7.42 (95\%CI -16.7, 1.85) $p=0.12$.

\section{Discussion}

There was a statistically significant decline in numbers of patients seen during the doctors' strike and nurses' strike but not during the $\mathrm{CO}$ strike period. This decline in patient numbers continued into the poststrike period. It is possible that even 3 months after the strikes had ceased patients were skeptical that services were fully available. After adjusting for the decline in patient volume, there was still a significant decline in mortality during the same period. Nurses and $\mathrm{CO}$ strikes did not significantly impact mortality in this [24] assessment; therefore the main focus of our deliberation is the doctors' strike. During the doctors' strike examination of departmental level data showed that, maternity and neonatal departments had a significant decline in mortality. $\mathrm{KNH}$ had the highest mortality overall at baseline and during the strike periods, consistent with its role as a very high acuity national referral hospital. The extent to which different unionized cadres respected the strike lines for their other health care workers is not data that is available but is partially represented in the numbers of patients seen during the respective time periods. 


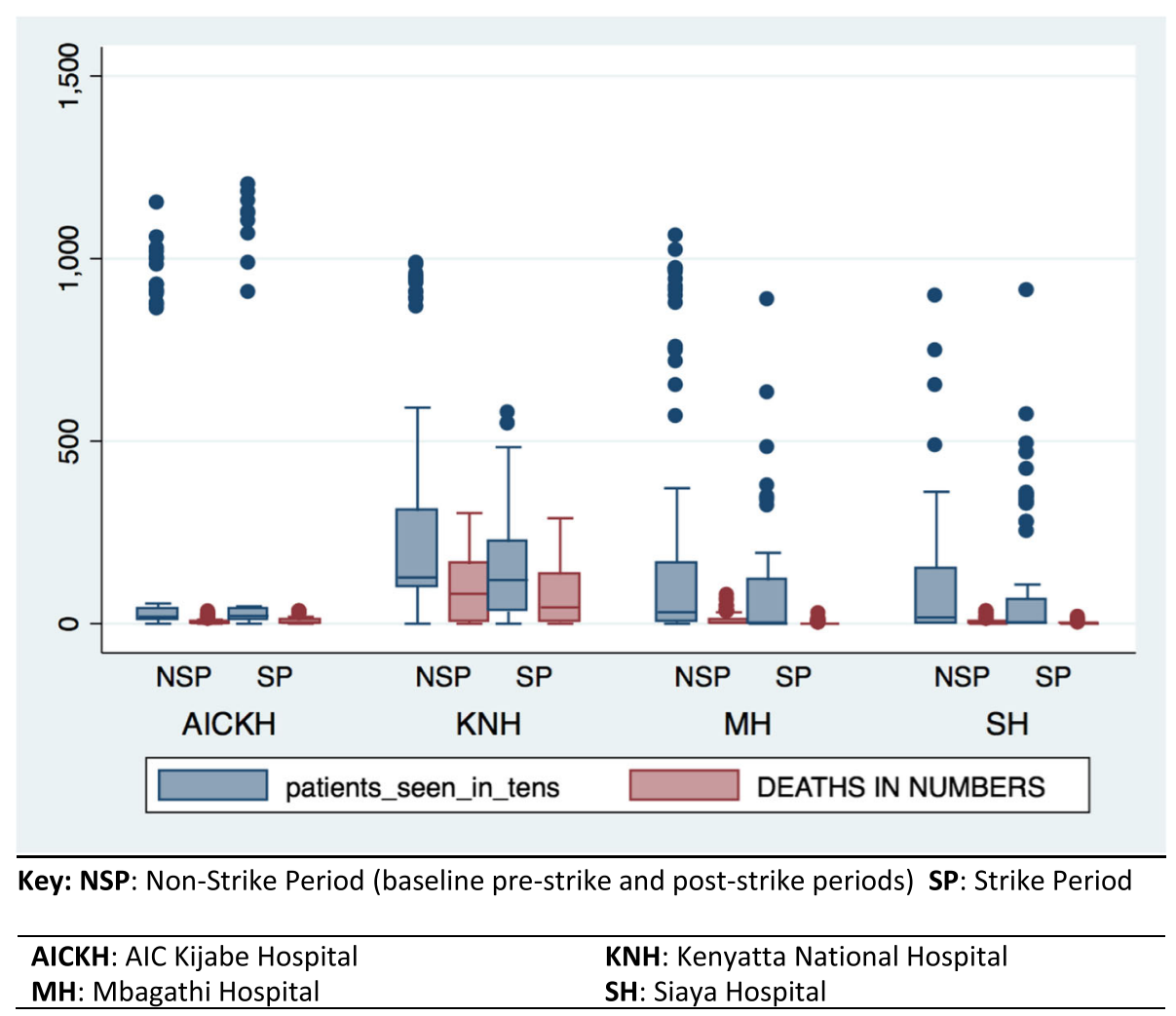

Fig. 1 Box plot of patients seen (in tens) versus deaths, categorized by strike and non-strike periods

Maternity/neonatal department had significantly lower mortality during the strike period. This could be explained by lower numbers of high obstetric risk patients accessing the facilities during the strikes. Alternatively, it may also be due to reduction in the numbers of unnecessary or elective surgical procedures, (Caesarian sections) and their attendant risks [1]. The ART clinic also saw a considerable decline in mortality, likely attributable to the large decline in numbers of patients visiting the clinic.

Our results are consistent with multiple studies in industrialized nations [1, 2, 22, 23, 25-27], yet they're somewhat surprising. Good facility based care have been shown to prevent excess mortality [28]. Nevertheless, there could be iatrogenic risks of hospital stays including hospital acquired infections, incorrect treatment, medical errors and complications from surgical procedures [29-32].

\section{Macro-mortality impact of strikes}

No adverse mortality impact of any of the health professionals' strike could be demonstrated. It is possible that patients died elsewhere. There is no death registry where macro-mortality in the catchment areas of the four facilities can be compared for trends in the strike and non- strike periods. In a population-based study of mortality impact of strikes, using demographic surveillance data, no change in the mortality during strike vs non-strike periods was noted [33].

Table 2 Mean baseline mortality Dec 2015-Nov 2016 (non-strike period) compared to reference hospital

\begin{tabular}{llllll}
\hline Facility & $\begin{array}{l}\text { Mean baseline mortality } \\
\text { out-patients }(95 \% \mathrm{Cl})\end{array}$ & $\begin{array}{l}\text { Mean baseline mortality } \\
\text { in-patients }(95 \% \mathrm{Cl})\end{array}$ & $\boldsymbol{p}$-value* & $\begin{array}{l}\text { All Baseline Mortality } \\
(95 \% \mathrm{Cl})\end{array}$ & $\boldsymbol{p}$-value \\
\hline AICKH & $2.46(1.38,3.54)$ & $6.34(3.76,8.92)$ & 0.04 & $5.03(3.25,6.81)$ & ref \\
KNH & $49.1(27.6,70.6)$ & $123(99.1,148)$ & 0.001 & $105(85.0,125)$ & $<0.0001$ \\
MH & $3.83(2.47,5.19)$ & $11.6(7.56,15.6)$ & 0.03 & $9.60(6.57,12.8)$ & 0.02 \\
SH & 0 & $6.00(3.63,8.37)$ & 0.002 & $4.27(2.50,6.04)$ & 0.55 \\
All facilities mortality baseline & $14.0(7.31,20.6)$ & $41.6(32.0,51.2)$ & 0.0008 & $41.5(32.5,50.4)$ & 0.0001 \\
\hline
\end{tabular}


Table 3 Baseline mortality versus mortality when different health workers are on strike in all facilities

\begin{tabular}{|c|c|c|c|c|c|}
\hline $\begin{array}{l}\text { Health Worker on } \\
\text { strike }\end{array}$ & $\begin{array}{l}\text { Mean baseline (non-strike mortality) } \\
\text { out-patient across all facilities }\end{array}$ & $\begin{array}{l}\text { Strike period out- } \\
\text { patient mortality } \\
\text { mean deaths ( } 95 \% \\
\text { Cl) }\end{array}$ & $\begin{array}{l}\text { Mean baseline (non-strike mortality) } \\
\text { in patient across all facilities }\end{array}$ & $\begin{array}{l}\text { Strike period in- } \\
\text { patient mortality } \\
\text { mean deaths ( } 95 \% \\
\text { Cl) }\end{array}$ & $\begin{array}{l}p^{-} \\
\text {value }^{\mathbf{a}}\end{array}$ \\
\hline Doctors & $15.1(8.43,21.8)$ & $6.32(2.02,10.6)$ & $45.3(35.3,55.3)$ & $19.4(9.59,29.2)$ & 0.11 \\
\hline Nurses & & $12.1(2.24,22.0)$ & & $40.6(26.0,55.1)$ & 0.03 \\
\hline Clinical Officers & & $8.20(-8.17,24.6)$ & & $44.8(17.6,72.1)$ & 0.13 \\
\hline $\begin{array}{l}\text { Combined time of all } \\
\text { cadres on strike }\end{array}$ & & $9.66(3.76,15.6)$ & & $32.2(22.5,41.8)$ & 0.007 \\
\hline
\end{tabular}

${ }^{a}$ significant differences between in and out patient mortality based on cadre on strike

Data from strikes in Los Angeles County also saw no population level mortality change [25].

\section{Mortality as a metric of impact}

Mortality is a 'late-stage' indicator of health status and may be a poor metric for the full impacts of health worker strikes [1]. It's possible that the disruption of health services impacts morbidity. Disruption in health services was associated with an increase in reported incidence of Chlamydia infections [34] and an increase in uncontrolled hypertension among known hypertensives on follow up, during a long physician strike [16]. Though we did not demonstrate mortality impacts, further study is needed to determine the morbidity effects of strikes.

\section{The role of decongestion}

Given that the numbers of patients coming to the public facilities significantly declined during the strike period, it is possible that the strike related mortality decline represents a correction in workload for facilities and staff, namely decongestion with possible benefits in the increased quality of care. The consistent decline in mortality in every department supports this. The converse finding in AICKH, further upholds this argument. The physicians' strike stretched the hospital's capacity and cite that increased mortality rates might be related to overstretched health workers with an attendant decline in quality of care as one possible explanation for the findings [35]. AICKH was an alternative facility accessible to many patients who might utilize a public hospital due to the relatively low user fees.

Thus, possibly in addition to fewer mortalities due to elective surgery, the decongestion of public facilities during strikes may account for the decreased mortality during strikes.

\section{Patient dumping}

$\mathrm{KNH}$ had the highest mortality at baseline and thereafter. It's the region's most specialized public facility and largest teaching and referral hospital and likely receives the more severely ill patients. This may explain the

Table 4 Multiple linear regression model adjusting for patient numbers, staff cadre on strike, strike period, department and facility

\begin{tabular}{|c|c|c|c|c|}
\hline Variable & Category & Beta coefficient $(95 \% \mathrm{Cl})$ & $\boldsymbol{p}$-value & R squared \\
\hline Total number of patients seen & N/A & $-.003(-.006,-.001)$ & 0.003 & $41.6 \%$ \\
\hline \multirow[t]{5}{*}{ Period } & Baseline (non-strike) & REF & & \\
\hline & Doctors' strike & $-19.0(-29.2,-8.87)$ & $<0.0001$ & \\
\hline & Nurses' strike & $-3.27(-14.7,8.05)$ & 0.57 & \\
\hline & Clinical Officers' strike & $-0.50(-13.9,12.9)$ & 0.94 & \\
\hline & Post-strike & $-7.42(-16.7,1.85)$ & 0.12 & \\
\hline \multirow[t]{5}{*}{ Department } & Casualty & REF & & \\
\hline & Maternity/neonatal & $-23.0(-41.0,-5.08)$ & 0.01 & \\
\hline & Medical/Surgical & $6.71(-11.4,25.0)$ & 0.47 & \\
\hline & Pediatric in and out-patient & $-11.4(-28.3,5.49)$ & 0.19 & \\
\hline & ART Clinic & $-37.6(-54.1,-21.0)$ & $<0.0001$ & \\
\hline \multirow[t]{4}{*}{ Facility } & $\mathrm{AlCKH}$ & REF & & \\
\hline & $\mathrm{KNH}$ & $82.0(72.0,92.1)$ & $<0.0001$ & \\
\hline & $\mathrm{MH}$ & $-5.58(-15.5,4.33)$ & 0.27 & \\
\hline & $\mathrm{SH}$ & $-7.54(-17.6,2.57)$ & 0.14 & \\
\hline
\end{tabular}


Table 5 Determinants of the numbers of patients seen adjusted for: facility, department, strike period

\begin{tabular}{llll}
\hline Variable & Category & Beta coefficient $(95 \% \mathrm{Cl})$ & $\boldsymbol{p}$-value \\
\hline Period & Baseline (non-strike) & REF & $<0.0001$ \\
& Doctors' strike & $-649(-951,-347)$ & 0.04 \\
& Nurses' strike & $-353(-692,-13.8)$ & 0.24 \\
& Clinical Officers' strike & $-239(-641,162)$ & 0.002 \\
Post-strike & $-435(-712,-158)$ & $<0.0001$ \\
Department & Casualty & REF & $<0.0001$ \\
& Maternity & $-6085(-6422,-5748)$ & $<0.0001$ \\
& Medical/Surgical & $-6034(-6384,-5684)$ & $<0.0001$ \\
Facility & Pediatric in and out-patient & $-5382(-5728,-5036)$ & $<0.0001$ \\
& ART Clinic & $-4453(-4842,-4063)$ & 0.98 \\
AICKH & REF & 0.002 \\
\hline
\end{tabular}

significantly higher baseline mortality. Due to its geographical location, proximal to several large private hospitals it may also be much more subject to patient dumping, defined as transfer of patients from private facilities who are considered undesirable usually for financial reasons. These patients tend to be poor and seriously ill [36]. During the strike, fewer patients may have been transferred, contributing to the large decline in mortality.

\section{Strengths \& Limitations}

To our knowledge this is the first study that has quantified the mortality impacts of multiple cadres of health workers, across several departments in a number of facilities in Kenya. Most of the mortality records in the sampled facilities were complete, therefore the study findings are less subject to the biases of missing data.

There were several limitations. As this was an ecological study, it was not possible to discern whether patients who came in during the strike were different in any way from the non-strike period. If these patients had less serious morbidity, then that could explain decreased mortality during the strike. This would be quite unusual, since most patients cannot afford private health care, they're likely to keep away for trivial ailments during a strike. Some studies have shown no differences in the morbidity level of patients during the strike versus the non-strike period [25]. Further, such patients would likely have presented in the post-strike period with more severe morbidity. However, we observed no increase in mortality in the post-strike period, although the time period observed was shorter than previous intervals.
There were challenges obtaining information on the numbers and cadres of health personnel in the various departments for the period under study. Hence, we cannot speculate on workload or quality of care.

In previous studies, the mortality decline is speculatively attributed to a delay in recording deaths during the strike period or a low level of curtailment of services [1]. In all the facilities we sampled, month to month aggregate patient data were available in every department for the defined period.

Theoretically, the preservation of emergency services during the strike period could have contributed to the decline in mortality by stabilizing acutely ill patients increasing their survival after admission. The decline in the numbers of patients attending the facilities during the strike might have further improved quality of care. However, the study did not by design collect data on the severity of presenting illnesses, the numbers of providers who continued to work, or quality of care in the respective periods. Therefore, we cannot definitively conclude this. Furthermore, it has been shown in our settings the vast majority of the deaths occur outside a health facility, therefore a strike by curative health services might have less of an impact if a large proportion of the population are not attending hospital for treatment [33].

\section{Conclusion}

We recognize quantifying the health impacts of interventions, or absence thereof is often challenging. Interventions occur in complex environments and may require a long duration of observation to detect changes [34]. Nevertheless, we observed declines in facility based mortality during health worker strikes'. The decline is 
possibly associated with reduced patient volumes, we surmise that decongestion may have contributed. In a country where $80 \%$ of the Kenyans lack financial protection from health care costs, Judicious investment in the health infrastructure and staffing may decrease congestion and improve quality of care with possible mortality decline.

\section{Abbreviation}

AICKH: AIC Kijabe Hospital; ART: Anti-Retroviral Treatment Clinic; CO: Clinical Officer; IRB: Institutional Review Board; IRG: Internal Research Grant; KEMRI: Kenya Medical Research Institution; KNH: Kenyatta National Hospital; MH: Mbagathi Hospital; MO: Medical Officer; SH: Siaya Hospital;

SERU: Scientific Ethics and Review Unit; US: United States

\section{Acknowledgments}

Authors appreciate Elizabeth Chirchir for her invaluable assistance in collecting and cleaning the data. KEMRI-IRG program for giving merit to the research question.

\section{Authors' contributions}

GK, MBA, VN designed the study. GK oversaw data collection, analysed the study and wrote the manuscript. VN and MBA critically reviewed the manuscript and approved the final version.

\section{Funding}

This study was funded by KEMRI-Internal Research Grant Program (IRG). KEMRI had no role in the study design, decision to analyze and publish the data.

\section{Availability of data and materials}

The datasets used and/or analysed during the current study are available from the corresponding author on reasonable request.

\section{Ethics approval and consent to participate}

The study was reviewed and approved by the Kenya Medical Research Institution (KEMRI), Scientific Ethics and Review Unit (KEMRI-SERU 3602), the KNH Institutional Review Board (IRB) and the Kijabe Hospital Independent Ethics Review Committee waived requirements for Individual informed consent as the study was collecting aggregate, non-identifiable data at health facilities. Administrative permission was also obtained from the respective heads of hospital management teams to review monthly summaries.

\section{Consent for publication}

Not applicable.

\section{Competing interests}

the authors declare they have no competing interests.

\section{Author details}

${ }^{1}$ Centre for Respiratory Diseases Research-Kenya Medical Research Institute (KEMRI-CRDR), P.O. Box 62269-00200, Nairobi, Kenya. ${ }^{2}$ AIC Kijabe Mission Hospital, Kijabe, Kenya.

Received: 12 September 2019 Accepted: 18 May 2020

\section{Published online: 26 May 2020}

\section{References}

1. Cunningham SA, Mitchell K, Narayan KM, Yusuf S. Doctors' strikes and mortality: a review. Soc Sci Med. 2008;67(11):1784-8.

2. Stabler C, Schnurr L, Powell G, Stewart B, Guenter CA. Impact of a provincewide nurses' strike on medical care in a regional referral centre. Can Med Assoc J. 1984;4(1):127-57.

3. Irimu G, Ogero M, Mbevi G, Kariuki C, Gathara D, Akech S, Tsofa B, English M. Tackling health professionals' strikes: an essential part of health system strengthening in Kenya. BMJ Glob Health. 2018;3(6):e001136. https:/doi.org/ 10.1136/ bmjgh-2018-001136.
4. Adam MB, SM JAM, Steere M, Cook N, Chen WECT, Shirk A, Muma Nyagetuba JK, Hansen EN. Paediatric and obstetric outcomes at a faithbased hospital during the 100-day public sector physician strike in Kenya. BMJ Glob Health. 2018.

5. Pilpel D, Naggan L, Sarov B. Coping with health services disruption. Perceiving need and utilizing available services during a doctors' strike. Med Care. 1985;23(12):1372-80.

6. Kirigia JM, Barry SP. Health challenges in Africa and the way forward. Int Arch Med. 2008;1:27. https://doi.org/10.1186/1755-7682-1-27.

7. Health Sector Human Resource Strategy 2014-2018. Ministry of Health 2014

8. Mbindyo $P$, Blaauw $D$, English $M$. The role of clinical officers in the Kenyan health system: a question of perspective. Hum Resour Health. 2013;11:32.

9. Liefooghe R, Baliddawa JB, Kipruto EM, Vermeire C, De Munynck AO. From their own perspective. A Kenyan community's perception of tuberculosis. Tropical Med Int Health. 1997:2(8):809-21.

10. Ayuo PO, Diero LO, Owino-Ong'or WD, Mwangi AW. Causes of delay in diagnosis of pulmonary tuberculosis in patients attending a referral hospital in Western Kenya. East Afr Med J. 2008;85(6):263-8.

11. Buckle GC, Collins JP, Sumba PO, Nakalema B, Omenah D, Stiffler K, et al Factors influencing time to diagnosis and initiation of treatment of endemic Burkitt lymphoma among children in Uganda and western Kenya: a crosssectional survey. Infect Agent Cancer. 2013;8(1):36.

12. Onyango JF, Macharia IM. Delays in diagnosis, referral and management of head and neck cancer presenting at Kenyatta National Hospital. Nairobi East Afr Med J. 2006;83(4):85-91.

13. Kronborg H, Sievertsen HH, Wust M. Care around birth, infant and mother health and maternal health investments - evidence from a nurse strike. Soc Sci Med. 2016;150:201-11.

14. Pell C, Menaca A, Were F, Afrah NA, Chatio S, Manda-Taylor L, et al. Factors affecting antenatal care attendance: results from qualitative studies in Ghana, Kenya and Malawi. PLoS One. 2013;8(1):e53747.

15. National Hospital Insurance Fund. STRATEGIC PLAN 2014-2018. NHIF. 2014.

16. Marcovici OA, Slater PE, Ellencweig AY. Effects of the Israel doctors' strike on hypertension control in Ashdod. Eur J Epidemiol. 1987:3(1):30-4.

17. Chima SC. Doctor and healthcare workers strike: are they ethical or morally justifiable: another view. Curr Opin Anaesthesiol. 2020:33(2):203-10.

18. Okech TC, Lelegwe SL. Analysis of universal health coverage and equity on health Care in Kenya. Glob J Health Sci. 2016:8(7):218-27.

19. Tama E, Molyneux S, Waweru E, Tsofa B, Chuma J, Barasa E. Examining the implementation of the free maternity services policy in Kenya: a mixed methods process evaluation. Int J Health Policy Manag. 2018;7:603-13.

20. Irimu GW, Greene A, Gathara D, Kihara H, Maina C, Mbori-Ngacha D, Zurovac D, Migiro S, English M. Factors influencing performance of health workers in the management of seriously sick children at a Kenyan tertiary hospital - participatory action research. BMC Health Serv Res. 2014;14:59. https://doi.org/10.1186/1472-6963-14-59.

21. Gruber J, Kleiner SA. Do strikes kill? Evidence from New York state. NBER Working Paper. 2010;15855:127-57.

22. Belmin J, Chatellier G, Bellot P, Moulias R. Effect of two French nurses' strikes on mortality in a geriatric hospital. Am J Med. 1992;93(2):151-6.

23. Mustard CA, Harman CR, Hall PF, Derksen S. Impact of a nurses' strike on the cesarean birth rate. Am J Obstet Gynecol. 1995;172(2 Pt1):631-7.

24. Furnivall D, Bottle A, Aylin P. Retrospective analysis of the national impact of industrial action by English junior doctors in 2016. BMJ Open. 2018;8(1): e019319.

25. James JJ. Impacts of the medical malpractice slowdown in Los Angeles County: January 1976. Am J Public Health. 1979:69(5):437-43.

26. Bukovsky I, Herman A, Sherman D, Schreyer P, Arieli S, Caspi E. Perinatal outcome following physicians' strike of 1983. Isr J Med Sci:1985.

27. Aro S, Hosia P. Effects of a doctors' strike on primary care utilization in Varkaus, Finland. Scand J Prim Health Care. 1987.

28. Ghahiri A, Khosravi M. Maternal and neonatal morbidity and mortality rate in caesarean section and vaginal delivery. Advanced Biomedical Res. 2015:4.

29. Meharun-nissa Khaskheli SB, Sheeba A. latrogenic risks and maternal health: Issues and outcomes. Pak J Med Sci. 2014:30:111-5.

30. Green N, Johnson AP, Henderson KL, Muller-Pebody B, Thelwall S, Robotham JV, et al. Quantifying the burden of Hospital-acquired bloodstream infection in children in England by estimating excess length of Hospital stay and mortality using a multistate analysis of linked, routinely collected data. J Pediatric Infect Dis Soc. 2015;4(4):305-12. 
31. Maitland K, Kiguli S, Opoka RO, Engoru C, Olupot-Olupot P, Akech SO, et al. Mortality after fluid bolus in African children with severe infection. N Engl J Med. 2011;364(26):2483-95.

32. WHO. Global Tuberculosis Report; 2018. p. 2018

33. Ong'ayo G, Ooko M, Wang'ondu R, Bottomley C, Nyaguara A, Tsofa BK, et al. Impact of health workers' strikes on mortality between 2010-2016 in Kilifi, Kenya: a population based cohort analysis. Lancet Global Health. 2019.

34. Andrew D, Pinto EG, Al-Bargash D, Shahin R. Impact of a Labour Disruption Affecting Local Public Health on the Incidence of Chlamydia Infections in Toronto. PLoS One. 2013;8(11):e79375.

35. Abubakar IPL, Ariti C, Beynon R, Mangtani P, Sterne JA, Fine PE, Smith PG, Lipman M, Elliman D, Watson JM, Drumright LN, Whiting PF, Vynnycky E, Rodrigues LC. Systematic review and meta-analysis of the current evidence on the duration of protection by bacillus Calmette-Guérin vaccination against tuberculosis. Health Technol Assess. 2013.

36. Abel E. Patient dumping in New York City, 1877-1917. Am J Public Health. 2011;101(5):789-95.

\section{Publisher's Note}

Springer Nature remains neutral with regard to jurisdictional claims in published maps and institutional affiliations.

Ready to submit your research? Choose BMC and benefit from:

- fast, convenient online submission

- thorough peer review by experienced researchers in your field

- rapid publication on acceptance

- support for research data, including large and complex data types

- gold Open Access which fosters wider collaboration and increased citations

- maximum visibility for your research: over $100 \mathrm{M}$ website views per year

At $\mathrm{BMC}$, research is always in progress.

Learn more biomedcentral.com/submissions 